\title{
Assessment of Fetal Middle Cerebral Artery Systolic/Diastolic Ratio; for Predicting Fetal Outcome in Preeclampsia Patients Using Doppler Ultrasonography
}

\author{
Tagread Ahmed AbdAlla Elmahi ${ }^{*}$, Marwa H. Mohammed $\mathrm{MH}^{2}$, Ragaa Ahmed Aburaida ${ }^{2}$
}

\author{
${ }^{1}$ National Ribat University, Faculty of Radiology and Nuclear Medicine Science, Nile Street Burri, Postal Code 11111, Khartoum \\ Sudan \\ ${ }^{2}$ Faculties of Radiology Science and Medical Imaging, Alzaiem Alazhari University, Khartoum, Sudan
}

DOI: $10.36347 /$ sasjm.2022.v08i01.010

| Received: 07.12.2021 | Accepted: 10.01.2022 | Published: 28.01.2022

*Corresponding author: Tagread Ahmed AbdAlla Elmahi

National Ribat University, Faculty of Radiology and Nuclear Medicine Science, Nile Street Burri, Postal Code 11111, Khartoum Sudan

Preeclampsia (PE) is a pregnancy complication characterized by high blood pressure, albuminuria and edema. PE is leading cause of maternal and perinatal morbidity and mortality. The study aimed to assess the fetal middle cerebral artery (MCA) systolic diastolic ratio (S/D ratio) in PE patients. A prospective case-control study performed in Sudan at Omdurman Maternity Hospital, feto-maternal unit. $100 \mathrm{PE}$ patients and 120 healthy pregnant women matched for age, parity, and gestational age (GA) served as controls, all were subjected to routine ultrasound (US) followed by Doppler, the data was discussed and presented in percentage between patients age, GA, Parity, Diastolic, systolic and S/D Ratio. Doppler Analysis and its correlated to fetal outcome were discussed. Then statistically the results were analyzed. Doppler US results, from MCA considered as strong independent predictors in excluding adverse fetal outcome in PE.

Keywords: Doppler, Preeclampsia, maternal, perinatal, morbidity and mortality.

Copyright $\odot 2022$ The Author(s): This is an open-access article distributed under the terms of the Creative Commons Attribution 4.0 International License (CC BY-NC 4.0) which permits unrestricted use, distribution, and reproduction in any medium for non-commercial use provided the original author and source are credited.

\section{INTRODUCTION}

$\mathrm{PE}$ is a pregnancy-specific syndrome characterized by reduced organ perfusion secondary to vasospasm and endothelial pathophysiology. The reported incidence of $\mathrm{PE}$ is $5-8 \%$ [1]. This condition is a leading cause of maternal mortality and is responsible for considerable perinatal morbidity and mortality [2].

Although the etiology of pre-eclampsia remains unclear, current thought is that it follows from the failure of second-wave trophoblastic invasion in the late first and early second trimesters [3]. As a result of the failed replacement of the spiral artery muscularis, these arteries do not transform into low-resistance conduits and uteroplacental resistance fails to decrease. In order to improve placental perfusion, it may be hypothesized that there is compensatory production of vasodilator substances by the placenta [4].

Circulatory adaptation occurs in the form of cerebral vasodilatation, resulting in the redistribution of the cardiac output to provide an adequate oxygen supply to the brain. These changes, which help fetus to adapt to a hostile environment, may correlate with fetal neonatal health. Ante-partum assessment is based on the premise that identification and timed delivery of the hypoxic and acid tic fetus will prevent intrauterine fetal death and decrease the risk of long-term adverse effects. As a result of the prolonged fetal hypoxia [5], Fetal middle cerebral artery Doppler assessment is an important part of assessing fetal cardiovascular distress and fetal anemia or fetal hypoxia[4].

\section{OBJECTIVE}

To assess the fetal middle cerebral arterysystolic diastolic ratio in Preeclampsia patients using Doppler ultrasound for predicting fetal outcomes

\section{MATERIALS AND METHODS}

A descriptive cross sectional study, deal with Doppler ultrasonography findings for fetal MCA S/D ratio In PE Patients, 100 pregnant women with PE were 
enrolled in cases study, with viable singleton pregnancies, aged between 17 to 42 years old and had GA between 26-40 weeks which was documented by confirmed last menstrual period (LMP) and/or firsttrimester ultrasound dating, and did not have any obstetric or other morbidity except for PE were included in the study. PE was diagnosed according to the criteria of the International Society for the Study of Hypertension in Pregnancy: (Pre-eclampsia was defined as an arterial pressure greater than 140/90 $\mathrm{mm} \mathrm{Hg}$ on two separate occasions, with associated proteinuria ( $>1+$ on dipstick and/ or $>0.3 \mathrm{~g}$ litre \pm 1 on a $24-\mathrm{h}$ collection), occurring after the 20th week of gestation) [6]. The pregnancy could be complicated by IUGR, defined as ultrasound-estimated fetal weight of less than the 10th percentile for GA. 120 healthy pregnant women, matched for age, parity, and GA served as controls. A pregnant woman qualified for the study if she received no medication during the pregnancy except for iron supplement. All women performed in supine position, subjected to routine ultrasound followed by color Doppler, equipped with Toshiba Power Vision 6000 , with $3.5 \mathrm{MHz}$ convex transducer, flow measurements of fetal MCA S/D ratio were taken in a transverse plane slightly closer to base of skull, at the level of the greater wings of the sphenoid bone, the sample volume was placed after the origin of MCA. An angle of zero degree is used typically. One exam on each patient was carried out include one middle cerebral artery. Patient characteristics that were recorded include maternal age, parity, GA, blood pressure and MCA Doppler measurements, and then fetal outcome monitored and statistically analyzed.

Pregnant women with multiple pregnancies, having history of chronic hypertension, gestational diabetes, cardiac disease, and middle cerebral artery pathology were excluded. A previously reported mentioned that error for MCA measurements are less than $10 \%$ [7-9]. The data have been analyzed by a Statistical Package for Social Sciences (SPSS) by using various statistic methods, for tested the normality of distribution by visual comparison, comparing each distribution with the normal distribution.

Values are given as percentage or mean+/- SD. Decreases of $\mathrm{S} / \mathrm{D}$ ratio value, in the MCA were considered as an abnormal artery result.

Table-1: Clinical characteristics of cases group and their controls

\begin{tabular}{|c|c|c|}
\hline Parameter & $\begin{array}{c}\text { Preeclampsia }(\mathbf{n = 1 0 0}) \\
\text { Followed cases=88 }\end{array}$ & $\begin{array}{c}\text { Controls }(\mathbf{n = 1 2 0}) \\
\text { Followed cases=80 }\end{array}$ \\
\hline Age (means, years) & $5.86 \pm 28.77$ & $27.99 \pm 5.158$ \\
\hline Gestational age (means \pm Std., weeks) & $33.57 \pm 4.354$ & $33.14 \pm 4.848$ \\
\hline Systolic & $12.001 \pm 151.48$ & $113.72 \pm 6.847$ \\
\hline Diastolic & $8.672 \pm 99.12$ & $74.61 \pm 6.423$ \\
\hline S\D ratio & $.88371 \pm 3.2347$ & $3.7533 \pm .83525$ \\
\hline family history(n, \%) & $54(54 \%)$ & 0 \\
\hline Pregnancies with IUGR (n, \%) & $46(52.2 \%)$ & $2(2.5) \%$ \\
\hline Pregnancies with preterm $(\mathrm{n}, \%)$ & $29(33.0) \%$ & 0 \\
\hline Pregnancies with IUFD $(\mathrm{n}, \%)$ & $14(15.9) \%$ & 0 \\
\hline
\end{tabular}

Table-2: Shows severity of preeclampsia in cases group

\begin{tabular}{|c|c|c|c|c|}
\hline Severity & Frequency & Percent & Valid Percent & Cumulative Percent \\
\hline Mild & 55 & 55.0 & 55.0 & 55.0 \\
\hline Severe & 45 & 45.0 & 45.0 & 100.0 \\
\hline Total & 100 & 100.0 & 100.0 & \\
\hline
\end{tabular}

Table-3: Shows frequency distribution of parity for cases group

\begin{tabular}{|c|c|c|c|c|}
\hline Parity & Frequency & Percent & $\begin{array}{c}\text { Valid } \\
\text { Percent }\end{array}$ & $\begin{array}{c}\text { Cumulative } \\
\text { Percent }\end{array}$ \\
\hline PG & 33 & 33.0 & 33.0 & 100.0 \\
\hline 1 & 14 & 14.0 & 14.0 & 14.0 \\
\hline 2 & 14 & 14.0 & 14.0 & 28.0 \\
\hline 3 & 14 & 14.0 & 14.0 & 42.0 \\
\hline Multiparous & 25 & 25.0 & 25.0 & 67.0 \\
\hline Total & 100 & 100.0 & 100.0 & \\
\hline
\end{tabular}


Table-4: Shows means and std. deviation of MCA SUD ratio for presence of IUGR, preterm delivery and IUFD in cases group

\begin{tabular}{|c|c|c|}
\hline \multicolumn{2}{|c|}{ Fetal outcomes } & SWD ratio (Mean\& Std. Deviation) \\
\hline \multirow{2}{*}{ IUGR } & No & $3.4407 \pm .99725$ \\
\cline { 2 - 3 } & Yes & $3.1148 \pm 3.114$ \\
\hline \multirow{2}{*}{ Preterm } & No & $3.3219 \pm .83246$ \\
\cline { 2 - 3 } & Yes & $3.1655 \pm .96394$ \\
\hline \multirow{2}{*}{ IUFD } & No & $3.3657 \pm .86112$ \\
\cline { 2 - 3 } & Yes & $2.7664 \pm .80028$ \\
\hline
\end{tabular}

Table-5: Shows means and std. deviation of MCA S/D ratio for severity of preeclampsia in cases group:

\begin{tabular}{|c|c|c|}
\hline \multirow{2}{*}{ Severity of PE } & \multicolumn{2}{|c|}{ S/D ratio } \\
\cline { 2 - 3 } & Means & Std. Deviation \\
\hline Mild & 3.4640 & .95547 \\
\hline Sever & 3.0380 & .71288 \\
\hline
\end{tabular}

Table-6: Independent sample t- test for equality of means in IUGR, preterm, IUFD and Severity of PE cases and MCA S\D ratio in cases group

\begin{tabular}{|c|c|c|c|c|c|c|c|}
\hline \multirow{3}{*}{ Characteristic } & \multirow{3}{*}{$\mathbf{T}$} & \multirow{3}{*}{ Dt } & \multirow{3}{*}{$\begin{array}{l}\text { Sig. }(2- \\
\text { tailed }\end{array}$} & \multicolumn{4}{|c|}{ t-test for Equality of Means } \\
\hline & & & & \multirow{2}{*}{$\begin{array}{c}\text { Means } \\
\text { Difference }\end{array}$} & \multirow{2}{*}{$\begin{array}{l}\text { Std. Error } \\
\text { Difference }\end{array}$} & \multicolumn{2}{|c|}{$\begin{array}{l}95 \% \text { Confidence Interval } \\
\text { of the Difference }\end{array}$} \\
\hline & & & & & & Lower & Upper \\
\hline \multirow{2}{*}{$\begin{array}{l}\text { S\D ratio } \\
\text { (IUGR) }\end{array}$} & $-1.765-$ & 86 & .081 & $-.32593-$ & .18462 & $-.69298-$ & .04108 \\
\hline & $-1.740-$ & 74.273 & .086 & $-.32593-$ & .18727 & $-.69905-$ & .04719 \\
\hline \multirow{2}{*}{$\begin{array}{l}\text { S\D ratio } \\
\text { (Preterm) }\end{array}$} & $-.786-$ & 86 & .434 & $-.15635-$ & .19899 & $-.55192-$ & .23923 \\
\hline & $-.747-$ & 49.105 & .459 & $-.15635-$ & .20925 & $-.57683-$ & .26414 \\
\hline \multirow{2}{*}{$\begin{array}{l}\mathrm{S} \backslash \mathrm{D} \text { ratio } \\
\text { (IUFD) }\end{array}$} & $-2.413-$ & 86 & .018 & $-.59925-$ & .24837 & $-1.09300-$ & $-.10550-$ \\
\hline & $-2.538-$ & 19.155 & .020 & $-.59925-$ & .23615 & $-1.09325-$ & $-.10525-$ \\
\hline \multirow{2}{*}{$\begin{array}{c}\text { S\D ratio } \\
\text { (Severity of } \mathrm{PE})\end{array}$} & $-2.330-$ & 86 & .022 & $-.42596-$ & .18284 & $-.78943-$ & $-.06249-$ \\
\hline & $-2.392-$ & 85.036 & .019 & $-.42596-$ & .17811 & $-.78009-$ & $-.07183-$ \\
\hline
\end{tabular}

Table-7: Shows parity for controls group

\begin{tabular}{|c|c|c|c|c|}
\hline Parity & Frequency & Percent & Valid Percent & Cumulative Percent \\
\hline PG & 29 & 24.0 & 24.0 & 100.0 \\
\hline 1 & 15 & 12.4 & 12.4 & 12.4 \\
\hline 2 & 32 & 26.4 & 26.4 & 38.8 \\
\hline 3 & 15 & 12.4 & 12.4 & 51.2 \\
\hline Multiparous & 30 & 24.8 & 24.8 & 76.0 \\
\hline Total & 121 & 100.0 & 100.0 & \\
\hline
\end{tabular}

Table-8: Shows MCA-S/D ratio and outcome for controls group:

\begin{tabular}{|c|c|c|}
\hline \multicolumn{2}{|c|}{ Outcome } & S\D ratio \\
\hline \multirow{2}{*}{ IUGR } & Mean & 4.6500 \\
\cline { 2 - 3 } & $\mathrm{N}$ & 2 \\
\cline { 2 - 3 } & Std. Deviation & .49497 \\
\hline P Value & & 0.509 \\
\hline
\end{tabular}

Table-9: Shows independent sample t- test for equality of means in IUGR cases in controls group

\begin{tabular}{|c|c|c|c|c|c|c|c|}
\hline \multirow[t]{3}{*}{ IUGR } & \multirow{3}{*}{$\mathbf{T}$} & \multirow{3}{*}{ Dt } & \multirow{3}{*}{$\begin{array}{l}\text { Sig. }(2- \\
\text { tailed }\end{array}$} & \multicolumn{4}{|c|}{ t-test for Equality of Means } \\
\hline & & & & \multirow[t]{2}{*}{$\begin{array}{c}\text { Means } \\
\text { Difference }\end{array}$} & \multirow[t]{2}{*}{$\begin{array}{l}\text { Std. Error } \\
\text { Difference }\end{array}$} & \multicolumn{2}{|c|}{$\begin{array}{l}\text { 95\% Confidence Interval } \\
\text { of the Difference }\end{array}$} \\
\hline & & & & & & Lower & Upper \\
\hline \multirow{2}{*}{$\begin{array}{l}\mathrm{S} \backslash \mathrm{D} \\
\text { ratio }\end{array}$} & 1.311 & 78 & .194 & .53067 & .40472 & $-.27506-$ & 1.33639 \\
\hline & 1.513 & 4.770 & .193 & .53067 & .35069 & $-.38407-$ & 1.44540 \\
\hline
\end{tabular}


Table-10: t-test for equality of means for cases and controls groups:

\begin{tabular}{|c|c|c|c|c|c|c|c|}
\hline \multirow{2}{*}{$\begin{array}{c}\text { Cases } \\
\text { and } \\
\text { controls }\end{array}$} & \multicolumn{1}{|c|}{} & $\mathbf{D}$ & $\begin{array}{c}\text { Sig.(2- } \\
\text { tailed }\end{array}$ & $\begin{array}{c}\text { Means } \\
\text { Difference }\end{array}$ & $\begin{array}{c}\text { Std. Error } \\
\text { Difference }\end{array}$ & $\begin{array}{c}\text { 95\% Confidence Interval } \\
\text { of the Difference }\end{array}$ \\
\cline { 6 - 8 } & & & & & & Lower & Upper \\
\hline \multirow{2}{*}{ SLD ratio } & 4.466 & 218 & .000 & .5186 & .1161 & .2898 & .7475 \\
\cline { 2 - 8 } & 4.443 & 206.197 & .000 & .5186 & .1167 & .2885 & .7487 \\
\hline
\end{tabular}

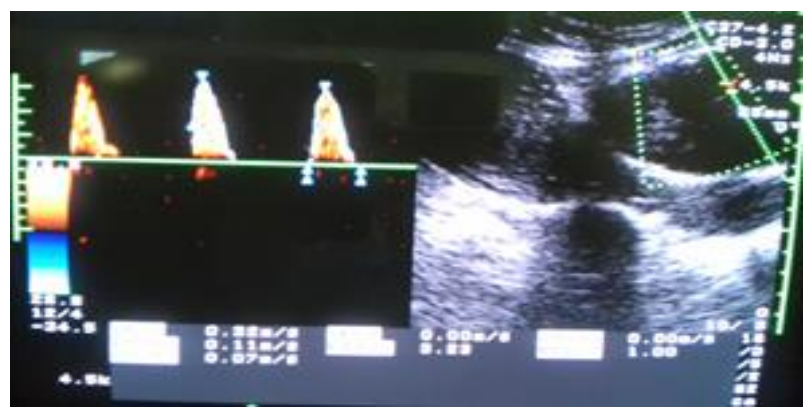

Image-1: MCA Wave Forms in PE Patient with 33 years, PG, 35 weeks 2 .2S/D ratio, preterm delivery and IUFD, (Absent Ed).

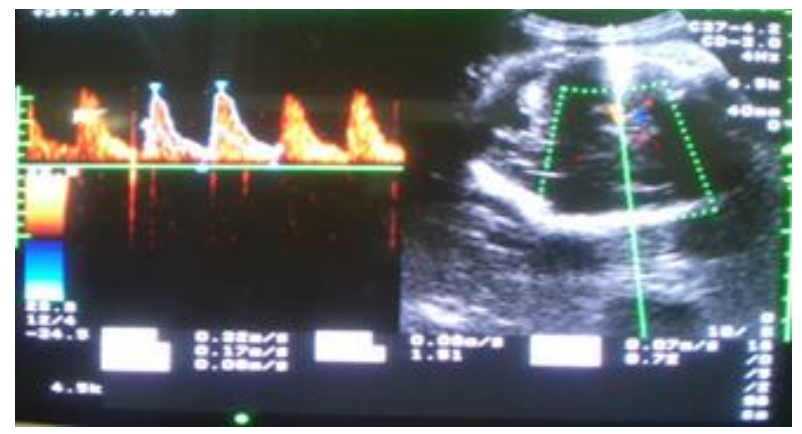

Image-2: MCA wave forms in PE with 22yr., III, 31 weeks, $3.5 \mathrm{~S} / \mathrm{D}$ ratio

\section{DISCUSSION}

Our study was hypothesized that MCA S/D ratio is predictive of the development of adverse perinatal outcome in PE patients, this supports our previous study which showing a reduced MCA-RI is a sensitive method for assessing IUGR.

In this study: 220 cases sub-divided in two groups: 100 cases group and 120 controls group. Mean maternal age was $28.77 \pm 5.86$ for the cases and $27.99 \pm 5.15$ for the controls (table1), so it shows no differences between study groups .This show difference with Lopez-Mendez et al. [10] whom reported that maternal age was PE risk factor with differences among groups which they study, this differentiation may be due to their small sample volume.

Out of 100 cases group (33.3\%) were primigravida (PG) (table 3) where in controls group out of 120 patients $24 \%$ were PG (table7), 54\% of cases have had family history of PE, where in controls group there were no one (table 1), these results supports the facts that nulliparity and family history of PE have been supported as PE risk factors in several studies [11, 12]. The mean of GA was $33.57 \pm 4.35$ for the cases. And
33.14 \pm-4.48 for controls (table 1), so it shows no differences between study groups. The mean of diastolic was $99.12 \pm 8.67$ and of systolic was $151.48 \pm 12.001$ for cases group, 74.61 \pm 6.423 and $113.72 \pm 6.84$ respectively for controls group (table 1 ).

The mean of S/D ratio was $3.2 \pm 0.88$ for cases group and $3.7 \pm 0.83$ for controls group. Regarding severity of PE $55 \%$ present with mild PE, with the mean: $3.4 \pm 0.95 \mathrm{~S} / \mathrm{D}$ ratio, versus $45 \%$ present with sever PE with the mean: $3.0 \pm \mathrm{S} / \mathrm{D}$ ratio, (table $2 \& 5$ ) Padmini C. P.et al. [13] found that Out of 80 cases, 41 cases $(52 \%)$ were mild PE and 39 cases $(48 \%)$ were severe PE. From 100 cases group and 120 controls group 88cases and 80 cases respectively were followed up, 52.3\% from cases group developed IUGR(table1), with the means: $3.1 \pm 0.72$ for S/D ratio (table4), with Significant 2-tailed PV 0.086 with 95\% Confidence Interval of the Difference, (table 6). Versus $47.7 \%$ not developed IUGR with means: $3.4 \pm 0.99$. Where in controls were $2.5 \%$ (table1) with means $4.6 \pm 0.49$ S/D ratio, (table8).

A number of longitudinal studies have assessed several fetal vessels with Doppler US and have reported that the cerebral circulation is of the first blood flows to become abnormal in IUGR $[14,15]$. Abnormal umbilical Doppler indices and abnormal cerebralumbilical ratio are strong predictors of IUGR and of adverse perinatal outcome in preeclampsia [16].

Preterm delivery present in 33\% cases group (table1), with means $3.1 \pm 0.96 \mathrm{~S} / \mathrm{D}$ ratio, (table4), versus $67 \%$ did not with means $3.3 \pm 0.83$ with Significant 2-tailed PV 0.459 S D ratio, with 95\% Confidence Interval of the Difference, (table 6). 15.9\% from cases group shows IUFD (table1), with the means: $2.7 \pm 0.80 \mathrm{~S} / \mathrm{D}$ ratio, (table4), versus $84.1 \mathrm{did}$ not shows IUFD, with means $3.3 \pm 0.86 \mathrm{~S} / \mathrm{D}$ ratio, with Significant 2-tailed PV 0.020 with $95 \%$ Confidence Interval of the Difference, (table 6).

These results matching B. Mallikarjunappa et al. [17] results that found among $100 \mathrm{PE}$ cases, preterm deliveries $32 \%$, perinatal death $16 \%$, low birth weight $38 \%$, fetal distress $14 \%$.

(Means under 3.27 S/D ratios, is consider abnormal). When we study over all cases and controls group MCA-S/D ratio, t-test for equality of means significant 2-tailed was 0.000 for S\D ratio with $95 \%$ confidence interval (table (10). 


\section{CONCLUSION}

There was a strong correlation between the MCA S/D ratio and adverse neonatal outcome in pregnant women with preeclampsia. Doppler study should be the primary tool of choice for fetal surveillance in PE patients. In our study the values of MCA-S/D ratio in PE patients were found reduced and play an important role in monitoring the fetal growth and thereby may help to determine the optimal time for delivery, so it is useful guide to reduce perinatal mortality and morbidity, and helps us to take time to plan and manage the patients in future deliveries.

\section{REFERENCES}

1. Cunningham, F. G. (2005). Hypertensive disorders in pregnancy. Williams obstetrics.

2. Hall, M. (2001). Why mothers die 1997-1999: The Confidential enquiries into maternal deaths in the United Kingdom. 5th Report of the National Confidential Enquiries.

3. Crews, J. K., Herrington, J. N., Granger, J. P., \& Khalil, R. A. (2000). Decreased endotheliumdependent vascular relaxation during reduction of uterine perfusion pressure in pregnant rat. Hypertension, 35(1), 367-372.

4. Walsh, S. K., English, F. A., Johns, E. J., \& Kenny, L. C. (2009). Plasma-mediated vascular dysfunction in the reduced uterine perfusion pressure model of preeclampsia: a microvascular characterization. Hypertension, 54(2), 345-351.

5. Weiner, Z., Farmakides, G., Schulman, H., \& Penny, B. (1994). Central and peripheral hemodynamic changes in fetuses with absent enddiastolic velocity in umbilical artery: correlation with computerized fetal heart rate pattern. American journal of obstetrics and gynecology, 170(2), 509-515.

6. Todros, T., Bontempo, S., Piccoli, E., Ietta, F., Romagnoli, R., Biolcati, M., ... \& Paulesu, L. (2002). New evidence for the role of infection in the pathogenesis of preeclampsia: increased levels of Macrophage migration Inhibitory Factor (MIF). In 13th World Congress of the International Society for the Study of Hypertension in Pregnancy (ISSHP) (Vol. 22, pp. S70-P101). -.

7. Aaslid, R., Markwalder, T. M., \& Nornes, H. (1982). Noninvasive transcranial Doppler ultrasound recording of flow velocity in basal cerebral arteries. Journal of neurosurgery, 57(6), 769-774.
8. Belfort, M. A., Tooke-Miller, C., Varner, M., Saade, G., Grunewald, C., Nisell, H., \& Herd, J. A. (2000). Evaluation of a noninvasive transcranial Doppler and blood pressure-based method for the assessment of cerebral perfusion pressure in pregnant women. Hypertension in pregnancy, 19(3), 331-340.

9. Arnolds, B. J., \& von Reutern, G. M. (1986). Transcranial Dopplersonography. Examination technique and normal reference values. Ultrasound in medicine \& biology, 12(2), 115-123.

10. Lopez-Mendez, M. A., Martinez-Gaytan, V., Cortes-Flores, R., Ramos-Gonzalez, R. M., OchoaTorres, M. A., Garza-Veloz, I., ... \& MartinezFierro, M. L. (2013). Doppler ultrasound evaluation in preeclampsia. BMC research notes, 6(1), 1-6.

11. Duckitt, K., \& Harrington, D. (2005). Risk factors for pre-eclampsia at antenatal booking: systematic review of controlled studies. Bmj, 330(7491), 565.

12. Kaaja, R. (2008). Predictors and risk factors of preeclampsia. Minerva ginecologica, 60(5), 421-429.

13. Padmini, C. P., Das, P., Chaitra, R., \& Adithya, M. S. (2016). Role of Doppler indices of umbilical and middle cerebral artery in prediction of perinatal outcome in preeclampsia. International journal of reproduction, contraception, obstetrics and gynecology, 5(3), 845-850.

14. Ozcan, T., Sbracia, M., d'Ancona, R. L., Copel, J. A., \& Mari, G. (1998). Arterial and venous Doppler velocimetry in the severely growth-restricted fetus and associations with adverse perinatal outcome. Ultrasound in Obstetrics and Gynecology: The Official Journal of the International Society of Ultrasound in Obstetrics and Gynecology, 12(1), 39-44.

15. Ferrazzi, E., Bozzo, M., Rigano, S., Bellotti, M., Morabito, A., Pardi, G., ... \& Galan, H. L. (2002). Temporal sequence of abnormal Doppler changes in the peripheral and central circulatory systems of the severely growth-restricted fetus. Ultrasound in Obstetrics and Gynecology, 19(2), 140-146.

16. Özeren, M., Dinç, H., Ekmen, Ü., Senekayli, C., \& Aydemir, V. (1999). Umbilical and middle cerebral artery Doppler indices in patients with preeclampsia. European Journal of Obstetrics \& Gynecology and Reproductive Biology, 82(1), 1116.

17. Mallikarjunappa, B., Harish, H., Ashish, S. R., \& Pukale, R. S. (2013). Doppler changes in preeclampsia. JIMSA, 26(4), 215-16. 